Table 1. Comparison of the Mean Percentages of Each OUtcome in Biology, General Science, Chemistry and Physics Papers, 'O'-Level G.C.E. OH FOUR BOARDS, 1948-64 Northern Universities Welsh Cambridge oxford \begin{tabular}{l}
$488^{\prime} 60{ }^{\prime} 63$ \\
\hline
\end{tabular}

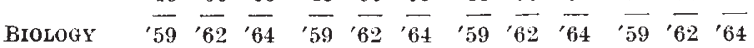
$\begin{array}{lllllllllllll}\text { (1) } \begin{array}{c}\text { Aequisition } \\ \text { of facts }\end{array} & 78 & 84 & 93 & 90 & 91 & 92 & 84 & 89 & 91 & 85 & 85 & 85\end{array}$

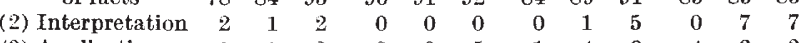
$\begin{array}{lrrrrrrrrrrrr}\text { (3) Application } & 1 & 1 & 2 & 0 & 0 & 5 & 1 & 4 & 0 & 4 & 3 & 3\end{array}$

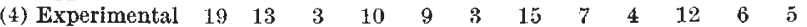
GeNeral Science

(1) Acquisition $\quad \begin{array}{lllllllllllll}58 & 53 & 60 & 78 & - & 82 & 68 & 63 & 70 & 66 & 71 & -\end{array}$ (2) Interpretation $14 \begin{array}{llllllllllll}14 & 25 & 13 & 5 & - & 3 & 7 & 9 & 7 & 6 & 10 & -\end{array}$ (3) Application $\quad \begin{array}{lllllllllllll}- & 19 & 13 & 19 & 9 & - & 12 & 12 & 19 & 18 & 15 & 16 & -\end{array}$

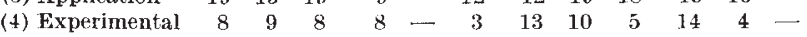
Chemistry

$\begin{array}{lllllllllllll}\text { (1) Acquisition } & 52 & 68 & 73 & 59 & 53 & 60 & 48 & 48 & 64 & 64 & 57 & 57\end{array}$

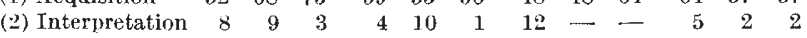
(3) Application $\quad \begin{array}{llllllllllll}17 & 11 & 16 & 11 & 18 & 32 & 12 & 37 & 25 & 14 & 21 & 26\end{array}$

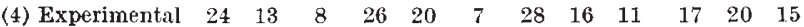
Physics

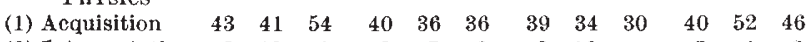

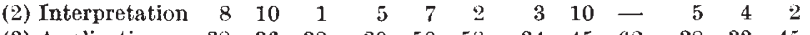
$\begin{array}{lllllllllllll}\text { (3) Application } & 38 & 36 & 38 & 39 & 50 & 58 & 34 & 45 & 62 & 38 & 33 & 45\end{array}$ (4) Experimental $\begin{array}{llllllllllll}12 & 14 & 7 & 16 & 9 & 4 & 95 & 12 & 8 & 18 & 12 & 7\end{array}$

jects in Britain and the United States will develop new teaching techniques which will also show how to give young pupils an understanding of the nature of the scientific process.

To-day the goal of mastering the factual content of a subject is not sufficient; there are other goals and needs at all levels of learning. The teaching of facts and method may go hand in hand. It is how the facts are learned and organized that makes a difference. Science is most effectively taught and learned when both pupils and teacher practise scientific investigation-when they devise experiments to solve problems and improvise simple apparatus for carrying them out.

One would expect general science, chemistry and physics papers to have smaller percentages of factual questions, because it has long been the standard practice in the teaching of physical sciences to apply scientific principles in numerical problems. About 20 per cent of the general science and chemistry papers and 40 per cent in physics are devoted to 'Application'. But, in general, these problems are formal and stereotyped and amount to little more than a memory test. There is no real, new scientific problem to solve.

About 20 per cent of chemistry papers and slightly less percentages in the other scientific subjects deal with experimental work. Hore again, this is rarely more than memory work, dealing with hoary experiments and demonstrations which have been thoroughly rehearsed. Rarely is a candidate expected to show imagination and ingenuity in devising oxperiments to test hypotheses which are new to him.

In their article, Crossland and Amos provide further evidence to show that sciontific method is virtually ignored in ' $\mathrm{O}$ '-level science courses. They discuss the implication of this deficiency for the education of all pupils and make suggestions for a shift in emphasis from mere memory work towards some appreciation of scientific methods in ' $\mathrm{O}$ '-level examinations.

The syllabuses in biology, general science, chemistry and physics of the nine General Certificate of Education Examining Boards were also examined. Apart from one Board, the Oxford and Cambridge, references to scientific method in biology, chemistry and physics are limited. In biology they are confined to a training in observation and recording; "Biological knowledge should be based-on observation of living plants and animals both in the laboratory and out of doors" is typical. Practical work in physical sciences is meant to give a training in skills and techniques, and in carrying out directions. In general science there are clearer signs that scientific method should be taught; for example, in the Cambridge syllabus we read " . ... the student should be led to some appreciation of scientific principles and methods by which they have been established". But the one Board which comes nearest to the treatment of scientific method is the Oxford and Cambridge. In its biology syllabus it states: (1) “. . (candidates) expected to draw conclusions from simple experiments which they perform". (2) "... to understand the necessity for control experiments". (3) "...questions ... which test powers of observation and reasoning of candidates". The general conclusion to be drawn from a study of the syllabuses is that only a limited amount of scientific method is expected at 'O'-level.

\title{
FUEL UTILIZATION
}

$\mathrm{F}$ UEL utilization is often regarded as the Cinderella of industry. Industries such as aireraft, motor cars, electronics and computers regard the designers of combustion chambers, boilers and furnaces as belonging to a comparatively primitive and unenterprising sector of industry. Such a view is only justified to the extent that the very small profit margins of old-established industries, which were in existence at the very beginning of the industrial revolution, allow only a small fraction of their annual turnover to be spent on research and development. In the case of units such as power station boilers or blast furnaces, each of which costs hundreds of thousands, if not millions, of pounds, the difficulties of developing a radically new and better design are immense, and unless there is a co-ordinating national development programme it is impossible to undertake the development of a greatly improved new type of appliance. Work with small pilot plant for such a new idea costs tens of thousands of pounds, and work with large pilot plant, which is essential to give answers to the economic questions of capital cost, reliability and required quality of constructional materials, costs in the range of hundreds of thousands of pounds.

It is, therefore, particularly timely and of national importance that the Institute of Fuel should have devoted the whole of a four-day conference to fuel research and development*.

The first paper in the conference was a directory of organizations carrying out research and development. This covers industrial firms and research organizations of the fuel industries, and ranges from small individual burner-makers up to organizations like Imperial Chemical Industries, Ltd., and Shell. Strangely enough, it does not, however, include any work done by universities and technical colleges, a number of which are doing valuable work at the small pilot plant and bench scale stages of applied research. The authors of the directory conclude that about 2,900 graduates and 5,000 non-graduates are working in the organizations covered by their survey and that the annual expenditure on fuel research and development excluding nuclear energy is just under $£ 20$ million. If we take it that the national annual fuel bill is of the order of $£ 2,000$ million, this comes out at 1 per cent, a very much lower figure than would be found in the more rapidly changing industries.

The first main session of the conference dealt with the organization of a research department, and the papers covered a number of interesting points, including Fronch, * Institute of Fuel, Proceedings at the Conference on Fuel Research and Development held at Eastbourne, 4th to 8th October, 1965 . Vol. 1 : Papers. J'p.
294. Conference Handbook. Pp. 14. (London: The Institute of Fuel, 1965.) 
American and Hungarian organizations. My criticism of this section would be that it does not give suffieient emphasis to the long-term practical objects of fuel research and development, namely, how to obtain the dosired output of the product with improved quality and regularity and reduced capital and running costs.

The next threo papers dealt with the approach to research and its assessment and communication. The special problem of fuol research is that it does not attempt to attract the most original-minded youngsters in the schools, but its advantage is that poople are prepared to discuss comparatively openly the new ideas which arise in these fields. The paper by the National Research and Development Council is very authoritative, as they have been working for many years on the best way of assessing new projects. Their particular fuel interests at the moment are connected with an automatic oil drill rig, fuel cells, high temperature combustion and new materials. Most new dovolopments in fuel technology pose new problems for materials either in terms of chemical resistance or strength at high temperatures. This is well illustrated by the fact that Lord Fisher wrote to Charles Parsons in 1909 suggesting that a Parsons turbine should be operated on combustion gases, whereas it was not for another 30 years that steels were availablo to provide the necessary strength under the required temperature conditions.

The remaining sessions of the conference follow very logically the stages of devolopment; the bench stage is illustrated by studies on pulverized coal, shock tubes and electrically augmented flames. These last two havo not yet found any commercial upplication, but have interesting possible applications in the field of high-temperature endothermic reactions or the production of reaction intermediates. The small and large pilot plant work is illustrated by work on flow patterns and a general account of the work of the International Flame Research Foundation on pulverized coal flames. The Ijmuiden experimental furnace of the International Flame Research Foundation can be regarded as a large pilot plant for the study of new kinds of flames for boilers and furnaces. Apart from this there is a great dearth of work with large pilot plant in the fuel field which makes it very difficult for any radically new process to be developed. This is because the cost of building a large pilot plant is at least one-tenth of the cost of the final equipment.

The final section dealing with applications is particularly satisfactory since it contains two examples of the successful application of two quite new processes, namely: (1) the reforming of naphtha to make town gas; (2) the development of the fuel for the advanced gas-cooled nuclear reactor together with some work on minor changes such as the injection of fuel into the tuyères of a blast furnace and the high intensity gas burner.

The discussion at the conference was very lively and there is no doubt that the conference provided a valuable stimulus to this very important branch of applied science.

M. W. Thring

\section{ATMOSPHERIC CLEAR AIR TURBULENCE}

\section{By DR. RICHARD L. MOORE and Prof. T. N. KRISHNAMURTI* \\ Douglas Aircraft Company, Inc., Long Beach, California}

$\mathrm{T}$ HE purpose of this article is to report on a matter of considerable interest to aircraft operations. A new approach has been made to the problem of clear air turbulence from the point of viow that energy is provided by tho transfer from large (or synoptic) scale flows toward the smaller-scale flow in the gravity wave spectra. Although the exact mechanies of such transfer have not been computed, the synoptic conditions favourable for tho rapid transfer of energy have been predicted from inviscid flow theory.

Synoptic evidence given by previous investigators, including Endlich ${ }^{1}$, Reiter ${ }^{2}$, and George ${ }^{3}$, from examination of weather maps has confirmed the suggestion that thero are certain well-recognized, large-scale patterns associated with the major outbreaks of clear air turbulence.

Endlich ${ }^{1}$ and Reiter ${ }^{2}$ notod that large vertical shears with strong backing of wind with height are frequently found in regions of clear air turbulence. The synoptic maps show a wosterly polar jet stream beneath a strong south-westerly sub-tropical jet stream. How, precisely, an instability arises in these large-scale flow configurations is not understood, and hence the precise modes of energy transfer from the larger to the smaller scales are as yet little known.

In most investigations of clear air turbulence the emphasis has been on tho use of local values of parameters such as the Richardson number (Endlich ${ }^{1}$ ) or the Seorer parameter $\left(\right.$ Reiter $\left.{ }^{2}\right)$. It is a basie premise of this article that these, or any other, parameters are only important in the region where turbulence is created, and in that region are only important at the time before inviseid flow breaks down into turbulence. Thus, once a turbulent oddy is excited it may be too late to look at these parameters since the flow field will be changed becnuse of the onset of turbulence.

In our invostigations the object is to explain clear air turbulence in terms of the following hypotheses: $(a)$ Shear

* University of California, Los Angeles, California. is generated rapidly in some region of the atmosphere to be called the source region. (b) The shear reaches a eritical value and the flow field becomes turbulent. (c) The turbulent flow field is carried away from the source region and gradually decays.

The shear is measured in terms of the vorticity vector, W, which is expanded in a Taylor's series, assuming the convection and diffusion of vorticity are small:

$$
\left.\left.\mathbf{W}(t)=\mathbf{W}(0)+\frac{\partial W}{\partial t}\right)_{0} t+\frac{\partial^{2} W}{\partial t^{2}}\right)_{0} \frac{t^{2}}{2}+\ldots
$$

In order to test the importance of effocts which are non-linear with time, we have examined, on weather maps, values of $\partial^{2} \mathbf{W} / \partial t^{2}$ calculated from a formula derived from the following theoretical approach (details of which have been over-simplified for the purpose of discussion).

The equation of motion in a fixed frame of reference for an inviscid fluid is:

$$
\frac{\mathrm{d} \mathbf{V}}{\mathrm{d} t}=-\frac{1}{\rho} \nabla p-g
$$

$p$ is the prossure, $p$ is the density; $-g$ is the gravitational force. $\mathrm{d} \mathbf{V} / \mathrm{d} t$ is the acceleration. The operation of $\frac{\partial}{\partial t}(\nabla \times)$ on equation (2) yields :

$$
\begin{aligned}
\frac{\partial}{\partial t}[\nabla \times & \left.\frac{\mathrm{d} \mathbf{V}}{\mathrm{d} t}\right]= \\
& -\frac{\partial}{\partial t}[R \nabla T \times \nabla \ln p] \simeq R \nabla T \times \nabla(\nabla \cdot \mathbf{V})
\end{aligned}
$$

The last step follows from the equation of continuity and the neglect of $\partial T / \partial t$. (Note. A more rigorous derivation by Moore ${ }^{4}$, which is too long for this articlo, has shown that if diabatic heating is noglected, the relation is:

$$
\begin{aligned}
\frac{\partial^{2} \mathbf{W}}{\partial t^{2}}+\frac{\partial}{\partial t}[(\mathbf{V} \cdot \nabla) \mathbf{W}-(\mathbf{W} \cdot \nabla) \mathbf{V}+\mathbf{W}(\nabla \cdot \mathbf{V})]= \\
\nabla \gamma R T \times \nabla(\nabla \cdot \mathbf{v})+\nabla R T \times \nabla(\mathbf{V} \cdot \nabla \ln p)+ \\
\nabla\{(\gamma-1) R T \nabla \cdot \mathbf{v}+\mathbf{V} \cdot \nabla R T\} \times \nabla \ln p
\end{aligned}
$$

